\title{
Aptitudes comparées de différentes espèces d'herbivores domestiques à ingérer et digérer des fourrages distribués à l'auge *
}

\author{
JP Dulphy, JP Jouany, W Martin-Rosset, M Thériez
}

INRA, centre de recherches de Clermont-Ferrand-Theix, F-63122 Saint-Genès-Champanelle, France

(Reçu le 2 avril 1992; accepté le 19 octobre 1993)

\begin{abstract}
Résumé - À partir des données de la bibliographie, nous avons comparé la capacité de différents herbivores domestiques à ingérer et à digérer les fourrages. Le mouton a été choisi comme animal témoin. Chez des ovins et des caprins n'ayant à couvrir que des besoins d'entretien, les quantités de matière sèche ingérées sont identiques, sauf pour les fourrages pauvres (foins tardifs, pailles...) que les caprins ont tendance à ingérer en quantités un peu plus élevées que les ovins $(+21 \%)$. Par kilogramme de poids vif, des bovins, n'ayant aussi à couvrir que des besoins d'entretien, ont tendance à moins ingérer que les ovins en jours longs mais en quantités comparables en jours courts. En revanche, les bovins ingèrent toujours plus que les ovins quand les quantités ingérées sont exprimées par $\mathrm{kg}$ de $\mathrm{P}^{0,75}$. Chez ces 3 espèces, les quantités ingérées varient avec la race, l'âge et les besoins. Ovins et cerfs ingèrent en quantités comparables les fourrages de bonne qualité, mais les cerfs ont tendance à mieux ingérer les fourrages de mauvaise qualité. Par kilogramme de poids vif, dromadaires et bovins ingéreraient des quantités comparables. Les lamas semblent moins ingérer que les ovins. Enfin, toujours par kilogramme de poids vif, chevaux et bovins ingèrent en moyenne des quantités comparables mais qui, pour les chevaux, ne sont pas reliées aux teneurs en constituants pariétaux des fourrages, contrairement à ce qui est observé chez les ruminants. Les caprins, peut-être parce qu'ils trient plus le fourrage qui leur est offert, digèrent un peu mieux les parois végétales que les ovins $(+1,3$ point), en particulier s'il s'agit de fourrages pauvres $(+2,7$ points). Globalement, la supériorité des caprins est cependant minime pour la matière organique. Les bovins en revanche digèrent en moyenne mieux que les ovins les parois végétales ( +3 points). Ils digèrent mieux les fourrages pauvres, mais non les fourrages de bonne qualité. À l'exception de la bruyère, les cerfs digèrent moins bien la matière organique des fourrages que les ovins $(-3,5$ points). Les Camélidés, à l'inverse, la digèrent nettement mieux que les ovins $(+3$ à +4 points en moyenne). Enfin les Équidés digèrent moins bien les fourrages que les ovins $(-2$ à -3 points pour les Légumineuses, -4 points pour les foins de Graminées et jusqu'à -8 points pour les pailles). Deux points importants sont en outre soulignés : les différences de digestibilité entre espèces sont plus nettes pour les fourrages pauvres, car elles ne concernent pratiquement que les parois végétales ; les herbivores tirent d'autant mieux partie des fourrages qu'ils sont d'un format élevé, car les capacités digestives évoluent en moyenne comme le poids vif des animaux, alors que les besoins ne sont proportionnels, grosso modo, qu'au poids métabolique $\left(\mathrm{P}^{0,75}\right)$.
\end{abstract}

ingestion / digestibilité / ovins / caprins / bovins / Cervidés / Camélidés / Équidés

* Communication faite à la 7 e Conférence sur la nutrition et l'alimentation des herbivores, Paris, 2526 mars 1992. Voir Ann Zootech 42, 116. 
Summary - A comparative study of intake and digestibility of forages in herbivores: a review. Using literature data, we compared the ability of different domestic herbivores to ingest and digest forages. Sheep were used as reference animals. In sheep and goats on maintenance diets, dry matter intake (DMI) was similar, except for low quality roughages (eg, late hay and straw), of which DMI was higher in goats $(+21 \%)$. After live-weight (LW) correction, DMI in bovines on maintenance diets was lower than in sheep, especially during long days (summer). During short days (winter) DMI in bovines was comparable to that in sheep. Nevertheless, the DMI expressed per $\mathrm{kg} L W^{0.75}$ was always higher in bovines. In the herbivore species above, DMI varies with age, breed and nutritional requirements. Sheep and deer ingested high quality forages at the same level, but deer appeared to ingest better low quality forages. The DMI per $\mathrm{kg} L W$ was similar for dromedaries and bovines, but with a tendency of being lower in dromedaries. Llamas seemed to have lower DMI than sheep. Finally, DMI per $\mathrm{kg} L W$ in horses was generally comparable with that in bovines. Unlike bovines, DMI in horses is unrelated to the forage cell-wall content. Cell-wall digestibility in goats in slightly higher (1.3 units) than in sheep. For low quality forages, however, this digestibility is markedly higher (+2.7 units) in goats, possibly due to a better selection of the ingested material. Organic matter (OM) digestibility, however, was similar in sheep and goats. The superiority of bovines over sheep to digest cell walls ( +3 units) was clear. Thus, digestion of especially low quality roughage was more efficient in bovines than in sheep. Forage OM digestibility, except that of heather, was lower in deer (-3.5 units) than in sheep. In contrast, digestibility in camelids was higher (3-4 units). Finally, the digestibility of different forages in horses was markedly lower than in sheep (-2-3 units for legumes, -4 units for grass hays and -8 units for straw). In conclusion to this review, 2 important findings can be underlined: (i) the digestibility differences between herbivores are more evident for low quality forages with high cell-wall contents; and (ii) the total $O M$ digestion is generally related to live-weight and nutritional requirements are proportional to $L W^{0,75}$, and so herbivores can more easily adjust their requirements when their body weight is increased.

intake / digestibility / ovines / goats / bovines / deers / camelids / horses

\section{INTRODUCTION}

Les herbivores domestiques, capables de digérer les parois végétales, sont les premiers utilisateurs des espaces naturels ou semi-naturels, très diversifiés. II est justifié alors de rechercher les espèces les mieux adaptées aux espaces à utiliser.

L'aptitude des herbivores à vivre et à produire est, pour une large part, liée à leurs capacités à ingérer et à digérer la végétation. Celles-ci sont difficiles à mesurer à l'extérieur, et restent très dépendantes du milieu. L'objectif de cette revue sera donc de comparer les comportements des différentes espèces dans des conditions expérimentales contrôlées, face aux différents types de fourrages.

Dans la littérature, la plupart des herbivores ont été comparés au mouton, es- pèce domestique probablement la mieux connue maintenant. Elle servira donc de référence. Dans l'ordre, seront traités d'abord les ruminants domestiques (ovins, caprins, bovins), puis les Cervidés, les $\mathrm{Ca}$ mélidés (Tylopodes) et, enfin, les Équidés, qui sont des herbivores non ruminants.

La comparaison portera sur l'utilisation des fourrages verts fauchés et distribués à l'auge, des foins, des pailles et parfois des ensilages.

\section{QUANTITÉS INGÉRÉES \\ PAR LES DIFFÉRENTES ESPÈCES}

\section{Mode d'expression}

La comparaison d'espèces très différentes par la taille nécessite la prise en compte 
de leur poids vif. Une correction est souvent faite par rapport au poids métabolique (PV0,75), pour tenir compte du fait que les besoins énergétiques sont proportionnels à cette expression du poids vif. Elle peut être faite également par rapport au poids vif (PV). Ces 2 modes d'expression sont intéressants. En effet, le premier permet d'estimer le degré de satisfaction des besoins, le second permet de comparer les espèces en considérant que les quantités ingérées dépendent en grande partie des capacités digestives, elles-mêmes dépendant du poids de l'animal. Compte tenu de cette remarque les deux modes d'expression seront utilisés.

\section{Ovins}

Chez le mouton "standard" (bélier adulte castré de race Texel pesant $60 \mathrm{~kg}$ ), les quantités de matière sèche (MS) de fourrages verts volontairement ingérées varient entre 14 (fourrages très tardifs contenant plus de $350 \mathrm{~g}$ de cellulose brute - CB - par kg de MS) et 32 (fourrages précoces ayant moins de $200 \mathrm{~g}$ de $\mathrm{CB}$ par $\mathrm{kg}$ de MS) $\mathrm{g} / \mathrm{kg}$ PV par jour, soit de 40 à $90 \mathrm{~g} / \mathrm{kg}$ PV0,75 (Demarquilly et al, 1981). Ces quantités diminuent avec le vieillissement de la plante, qui se traduit par l'augmentation de sa teneur en cellulose brute : on observe une baisse moyenne de 0,189 g/ $\mathrm{kg} \mathrm{P}^{0,75}$ par $\mathrm{g}$ de $\mathrm{CB}$. À même teneur en cellulose brute, les quantités ingérées sont plus élevées pour les Légumineuses que les Graminées.

Les quantités de foin volontairement ingérées varient de 12 à $27 \mathrm{~g} / \mathrm{kg}$ de $\mathrm{PV}$, soit de 33 à $75 \mathrm{~g} / \mathrm{kg} \mathrm{P0,75}$. Ces quantités diminuent aussi lorsque la teneur en cellulose brute augmente : la baisse observée est, en moyenne de $0,166 \mathrm{~g} / \mathrm{kg} \mathrm{P}^{0,75}$ par $\mathrm{g}$ de $\mathrm{CB}$. Les quantités ingérées sont plus élevées également pour les Légumineuses que pour les Graminées (Demarquilly et al, 1981), mais elles sont comparables à même teneur en parois (NDF) de ces 2 types de fourrages (Dulphy et al, 1990b). De plus, ces quantités diminuent avec la dégradation des conditions de la fenaison (Demarquilly et al, 1981). II est très probable cependant que la diminution observée entre fourrages verts et foins préparés dans de bonnes conditions soit due avant tout à un effet de la saison d'étude, les fourrages verts étant distribués en jours longs et les foins en jours courts. En effet, Michalet-Doreau et Gatel (1988) ont observé, chez le mouton, un niveau d'ingestion bien plus élevé en été qu'en hiver indépendamment de la nature du fourrage. La validité des mesures pour les comparaisons d'espèces animales n'est pas remise en cause par cette remarque car, en général, les fourrages verts sont consommés en jours longs et les fourrages conservés en jours courts. Quelle que soit leur origine, les écarts observés (effet conservation ou effet photopériode) se retrouvent donc dans la pratique. Enfin, les quantités de MS de paille ingérées sont faibles, de l'ordre en moyenne de $11 \mathrm{~g} / \mathrm{kg}$ de PV (avec $5 \mathrm{~g}$ de concentré), soit $31 \mathrm{~g} / \mathrm{kg} \mathrm{P}^{0,75}$, mais très variables d'une paille à l'autre (Andrieu et Demarquilly, 1987).

Les brebis taries ont une capacité d'ingestion comparable à celle du mouton standard (tableau I). Cette capacité est multipliée par 1,75 et 1,40 respectivement pour des brebis en début de lactation produisant $2 ; 75 \mathrm{~kg}$ de lait et en fin de lactation produisant $0,5 \mathrm{~kg}$ de lait (Bocquier et al, 1988).

\section{Caprins}

Les quantités ingérées de 113 fourrages par des caprins et des ovins n'ayant la plupart du temps que des dépenses d'entre- 
Tableau I. Capacité d'ingestion des principaux types d'herbivores domestiques exprimée (d'après Alimentation des bovins, ovins et caprins, INRA, 1988) par l'ingestion du fourrage standard.

\begin{tabular}{|c|c|c|c|c|}
\hline \multirow[t]{2}{*}{ Animaux } & \multirow[t]{2}{*}{ Poids vif $(\mathrm{kg})$} & \multirow[t]{2}{*}{ Caractéristiques } & \multicolumn{2}{|c|}{ Quantités de MS ingérées } \\
\hline & & & $g / k g P^{0,75}$ & $g / k g P V$ \\
\hline Bélier castré & 60 & Mouton standard & 75 & 27 \\
\hline Brebis tarie & 60 & État moyen & 79 & 28 \\
\hline Brebis allaitante & 60 & Début lactation $(2,75 \mathrm{~kg})$ & 139 & 50 \\
\hline Brebis allaitante & 60 & Fin lactation $(0,5 \mathrm{~kg})$ & 111 & 40 \\
\hline Bouc & 80 & Entretien & 79 & 26 \\
\hline Chèvre & 60 & Entretien & 80 & 29 \\
\hline Chèvre & 60 & Milieu lactation $(5 \mathrm{~kg})$ & 134 & 48 \\
\hline Chèvre & 60 & Fin lactation $(2 \mathrm{~kg})$ & 102 & 36 \\
\hline Génisse Holstein & 300 & 1 an & 94 & 23 \\
\hline Génisse $\mathrm{CH}$ ou SL & 300 & 1 an & 82 & 20 \\
\hline Génisse LI & 300 & 1 an & 69 & 17 \\
\hline Génisse Holstein & 500 & 2 ans & 96 & 20 \\
\hline Génisse $\mathrm{CH}$ ou SL & 500 & 2 ans & 88 & 19 \\
\hline Génisse LI & 500 & 2 ans & 81 & 17 \\
\hline \multirow[t]{2}{*}{ Taurillon race précoce } & 300 & & 93 & 22 \\
\hline & 500 & & 86 & 18 \\
\hline \multirow[t]{2}{*}{ Taurillon race int } & 300 & & 87 & 21 \\
\hline & 500 & & 81 & 17 \\
\hline \multirow[t]{2}{*}{ Taurillon race tardive } & 300 & & 83 & 20 \\
\hline & 500 & & 78 & 16 \\
\hline Vache laitière & 600 & Tarie & 111 & 22 \\
\hline Vache laitière & 600 & $25 \mathrm{~kg}$ de lait & 140 & 28 \\
\hline Vache allaitante & 650 & Tarie & 101 & 20 \\
\hline Vache allaitante & 650 & $3^{e / 4^{e}}$ mois de lactation & 123 & 24 \\
\hline
\end{tabular}

tien (tableau II) ont été comparées par différents auteurs. Les résultats montrent que les 2 espèces ingèrent presque les mêmes quantités de MS par rapport à leur poids vif. On note toutefois une ingestion supérieure de $+5 \%$ chez les caprins, pour l'ensemble des comparaisons, l'augmentation chez les caprins devenant plus importante $(+21 \%)$ avec les fourrages pauvres. Cette tendance, relativement nette, avait déjà été notée par Brown et Johnson (1984). Les écarts de quantités ingérées rapportées au poids métabolique sont plus faibles (respectivement 0 et $+13 \%$ pour les caprins).

Les chèvres à l'entretien ont donc une capacité d'ingestion comparable à celle des brebis (Morand-Fehr et Sauvant, 1988 ; tableau I). Les boucs sont comparables aux béliers castrés standards. Comme pour tous les animaux en lactation les capacités d'ingestion des chèvres augmentent nettement avec leurs besoins. 
Tableau II. Quantités ingérées comparées entre caprins et ovins nourris à volonté (QI).

\begin{tabular}{|c|c|c|c|c|c|c|}
\hline & \multicolumn{3}{|c|}{ Caprins } & \multicolumn{3}{|c|}{ Ovins } \\
\hline & $\begin{array}{l}\text { Poids vif } \\
\text { (kg) }\end{array}$ & $\begin{array}{c}Q I \\
(g / \mathrm{kg} P V)\end{array}$ & $\begin{array}{c}Q I \\
\left(g / \mathrm{kg}^{0,75}\right)\end{array}$ & $\begin{array}{l}\text { Poids vif } \\
\text { (kg) }\end{array}$ & $\begin{array}{c}Q I \\
(g / k g P V)\end{array}$ & $\begin{array}{c}Q l \\
\left(g / k g P^{0,75}\right)\end{array}$ \\
\hline $\begin{array}{l}\text { Tous fourrages } \\
(n=113)\end{array}$ & 36 & 22,2 & 54,4 & 44 & 21,1 & 54,4 \\
\hline $\begin{array}{l}\text { Fourrages très } \\
\text { tardifs et pailles } \\
(n=21)\end{array}$ & 32 & 17,8 & 42,5 & 42 & 14,7 & 37,5 \\
\hline
\end{tabular}

Références : Ruckebusch et Bost, 1963 ; Chenost, 1972; Jones et al, 1972; Geoffroy, 1974; Gihad, 1976; Wilson, 1977; Sharma et Rajora, 1977 ; Blanchard et al, 1980; Gihad et al, 1980; Alam et al, 1983; Doyle et al, 1984; Focant, 1984; Antoniou et Hadjipanayiotou, 1985; Alam et al, 1985; Brown et Johnson, 1985; Masson et al, 1986; Quick et Dehority, 1986; Huston et al, 1988; Masson et al, 1989; Dulphy et al, 1990a; Reid et al, 1990; Huguet, non publié.

\section{Bovins}

En prenant comme exemple une génisse Holstein de $400 \mathrm{~kg}$ (Dulphy et al, 1987), on observe que l'écart relatif entre les quantités ingérées des fourrages extrêmes est plus faible chez ces animaux que chez le mouton. En effet, les quantités de MS ingérées par des génisses varient respectivement de $24 \mathrm{~g} / \mathrm{kg}$ PV pour des repousses de luzerne en vert à $12 \mathrm{~g}$ pour une paille d'orge (distribuée avec un peu de tourteau de soja et de céréales), contre 32 à 11 pour les moutons (tableau III). En outre, les génisses ingèrent moins en $\mathrm{g} / \mathrm{kg}$ de PV de fourrages verts que les mou-

Tableau III. Quantités de MS ingérées comparées entre bovins (génisses Holstein de $400 \mathrm{~kg}$ ) et ovins (béliers castrés de $60 \mathrm{~kg}$ ) calculées d'après les Tables INRA (1988).

\begin{tabular}{|c|c|c|c|c|}
\hline & \multicolumn{2}{|c|}{ Génisses } & \multicolumn{2}{|c|}{ Beliers } \\
\hline & $g / k g P V .75$ & $g / k g P V$ & $g / k g P V 0,75$ & $g / k g P V$ \\
\hline \multicolumn{5}{|l|}{ Fourrages verts } \\
\hline Repousses de luzerne & 109,6 & 24,5 & 90,0 & 32,3 \\
\hline Fourrage standard & 95,0 & 21,2 & 75,0 & 27,0 \\
\hline Dactyle fin épiaison & 80,5 & 18,0 & 60,0 & 21,6 \\
\hline Fourrage tardif & 61,2 & 13,7 & 40,0 & 14,4 \\
\hline \multicolumn{5}{|l|}{ Fourrages secs } \\
\hline Foins très précoces & 99,9 & 22,3 & 63,7 & 22,9 \\
\hline Foins précoces & 90,2 & 20,2 & 56,8 & 20,4 \\
\hline Foins tardifs & 66,0 & 14,8 & 39,5 & 14,2 \\
\hline Paille d'orge & 52,8 & 11,8 & 30,3 & 10,9 \\
\hline
\end{tabular}


tons. On peut rappeler que les mesures étaient faites en jours longs, alors que la capacité d'ingestion des moutons est élevée (Michalet-Doreau et Gatel, 1988). Les fourrages secs sont ingérés par rapport au PV de façon comparable entre les 2 types d'animaux, avec une tendance plus favorable aux génisses pour les pailles, les mesures étant faites en jours courts.

Globalement, les résultats de I'INRA (1988), présentés plus haut, confirment ceux de la littérature (1965 à 1985), qui sont très nombreux. Quelques comparaisons $(n=87)$ sont données dans le tableau IV. Dans les essais présentés, les bovins (surtout des bouvillons et des vaches allaitantes) ont ingéré 19,5 de MS/ $\mathrm{kg}$ de $\mathrm{PV}$, contre $21,2 \mathrm{~g}$ pour les ovins, soit 85,6 et $61,1 \mathrm{~g}$ de $M S / k g P^{0,75}$ respectivement. Exprimés en $\mathrm{g} / \mathrm{kg}$ de $\mathrm{PV}$, les résultats sont en effet souvent supérieurs pour les ovins, peut-être à cause d'un effet saison.
Au-delà des effets de la nature des fourrages, 3 facteurs jouent un rôle important sur la capacité d'ingestion des bovins : leur race, leur âge et leurs besoins. Ainsi, à même poids vif, les génisses de race Frisonne ingèrent de 15 à $20 \%$ de plus que celles de race Salers (Agabriel et al, 1987). Les génisses de 2 ans ingèrent moins que celles de 1 an par $\mathrm{kg}$ de PV, qu'elles soient de race Frisonne $(20,1$ à 1 an contre $18,6 \mathrm{~g} / \mathrm{kg}$ PV à 2 ans) ou Salers (17 et $16,2 \mathrm{~g} / \mathrm{kg}$ PV). L'ingestion des vaches laitières est plus élevée que celle des génisses et augmente avec leur niveau de production de lait (Faverdin et al, 1987). Les capacités d'ingestion de différents types de bovins sont données dans le tableau I.

Les bovins sont peu affectés par la photopériode. En règle générale, pour des animaux de stade physiologique proche, ils ont donc un niveau d'ingestion exprimé en $\mathrm{g} / \mathrm{kg}$ PV qui est plutôt inférieur à celui des ovins, en été. En hiver, les résultats sont

Tableau IV. Exemple de comparaisons de quantités ingérées entre ovins et bovins.

\begin{tabular}{|c|c|c|c|c|}
\hline & \multicolumn{2}{|c|}{ Ovins } & \multicolumn{2}{|c|}{ Bovins } \\
\hline & $g / k g P^{0,75}$ & $g / k g P V$ & $g / k g P^{0,75}$ & $g / k g P V$ \\
\hline \multicolumn{5}{|l|}{ Comparaison moutons castrés adultes - bouvillons } \\
\hline Blaxter et al, $1966: 3$ fourrages déshydratés & 71,8 & - & 93,0 & - \\
\hline Engels et al, 1978 : 31 fourrages secs ou verts & 57,5 & 21,5 & 91,8 & 21,8 \\
\hline Playne, $1970: 3$ fourrages secs & 36,5 & 14,9 & 88,3 & 22,2 \\
\hline Playne, $1978: 1$ foin & 28,0 & 12,8 & 42,8 & 11,2 \\
\hline Rees et Little, $1980: 6$ fourrages secs & 54,9 & 22,6 & 64,2 & 14,8 \\
\hline Poppi et al, $1980: 8$ fourrages secs & 45,8 & 17,7 & 62,4 & 13,3 \\
\hline \multicolumn{5}{|l|}{ Comparaison moutons castrés adultes - vaches allaitantes } \\
\hline \multirow{3}{*}{ Vona et al, $1984: 28$ fourrages secs } & 80,6 & - & 114,2 & - \\
\hline & 65,5 & - & 86,7 & - \\
\hline & 72,6 & - & 71,9 & - \\
\hline \multicolumn{5}{|c|}{ Comparaison moutons castrés adultes - vaches laitières et taurillons } \\
\hline Chenost et Martin-Rosset, $1985: 7$ fourrages verts & s 73,6 & 26,4 & 96,2 & 20,3 \\
\hline
\end{tabular}


relativement comparables. Cependant, par rapport à leur poids métabolique, génisses, bouvillons et taurillons ingèrent toujours plus que les moutons, couvrant ainsi nettement mieux leurs besoins ( $c f$ Van Soest, 1982), et montrant une aptitude globale à tirer partie de la végétation, qui est supérieure aux ovins auxquels les éleveurs devront distribuer des fourrages plus digestibles ou en quantité suffisante pour permettre aux animaux de trier plus.

\section{Cervidés}

Les quantités ingérées par les cerfs varient, comme pour les autres ruminants, avec les caractéristiques des animaux et celles des fourrages, mais aussi, et de façon importante, avec la saison, en particulier à cause des modifications de la photopériode auxquelles les Cervidés sont particulièrement sensibles (Kay, 1985). Cette variation de la capacité d'ingestion est bien illustrée par le travail de Suttie et al (1983 et 1984). Elle rappelle celle observée chez les moutons. Ce phénomène doit donc être pris en compte pour comparer les espèces (Milne et al, 1978).

Par comparaison aux moutons, les cerfs ingèrent les fourrages de bonne qualité (di- gestibilité de la $M O>60 \%$ ) en quantité moindre (Milne et al, 1978) ou plus élevée (Kay et Goodall, 1976), mais en moyenne identique (tableau V). Pour ce qui concerne les fourrages de mauvaise qualité (digestibilité $<50 \%$ ), les cerfs ingèrent nettement plus (tableau $V$ ) que les moutons (Milne et al, 1978). II est vrai cependant que la valeur trouvée pour ces moutons était anormalement basse, plus faible que pour des pailles (Andrieu et Demarquilly, 1987).

\section{Camélidés}

Richard (1989) a synthétisé toutes les observations accessibles dans la littérature concernant les dromadaires étudiés dans leur milieu. II cite des valeurs de 14-15 g de $M S / k g$ PV pour la paille et 23 à $34 \mathrm{~g}$ pour les rations de bonne qualité. II note que, avec la paille, les valeurs observées sont comparables à celles trouvées pour les bovins en zone tropicale et légèrement supérieures à celles des animaux européens (12 g/kg PV pour les génisses). Kayouli et al (1992) trouvent, en moyenne, pour 3 rations différentes, $12 \mathrm{~g} / \mathrm{kg}$ de PV pour les dromadaires et $25 \mathrm{~g}$ pour les moutons. De même, Gihad et al (1989) trou-

Tableau V. Quantités ingérées comparées entre certs et moutons nourris à volonté (QI).

\begin{tabular}{|c|c|c|c|c|}
\hline & Cerfs & & & Moutons \\
\hline $\begin{array}{l}\text { Poids vif } \\
\text { (kg) }\end{array}$ & $\begin{array}{c}Q / \\
(g / \mathrm{kg} P V)\end{array}$ & $\begin{array}{c}Q \prime \\
\left(g / \mathrm{kg}^{0.75}\right)\end{array}$ & $\begin{array}{l}\text { Poids vif } \\
\text { (kg) }\end{array}$ & $\begin{array}{c}Q I \\
(g / \mathrm{kg} P V)\end{array}$ \\
\hline
\end{tabular}

\begin{tabular}{lcccccc}
$\begin{array}{l}\text { Fourrages de bonne } \\
\text { qualité } n=4[1,2]\end{array}$ & 69 & 25,1 & 72,3 & 58 & 26,0 & 71,7 \\
$\begin{array}{l}\text { Fourrages de mauvaise } \\
\text { qualité } n=5[1]\end{array}$ & 75 & 15,6 & 45,5 & 48 & 8,0 & 21,1 \\
\hline
\end{tabular}

Milne et al, 1978 [1]; Kay et Goodall, 1976 [2]. 
vent $11,4 \mathrm{~g} / \mathrm{kg}$ pour 3 régimes distribués à des dromadaires et $17,9 \mathrm{~g}$ pour les moutons. Pour des rations pauvres en azote, Richard (1989) indique des valeurs proches de $10 \mathrm{~g} / \mathrm{kg}$ de PV pour les dromadaires. Ces valeurs, qui sont considérées comme plutôt faibles, seraient peut-être dues à une mauvaise adaptation aux contraintes expérimentales. Bien que cela mérite confirmation, on pourrait donc retenir qu'exprimées en $\mathrm{g} / \mathrm{kg}$ PV les quantités ingérées par les dromadaires sont plus faibles que celles des moutons.

Les données concernant les lamas sont très peu nombreuses. Pour une paille, Warmington et al (1989) ont montré que ceux-ci avaient un niveau d'ingestion moyen de $12 \mathrm{~g} / \mathrm{kg} P V$, contre 12,5 pour des moutons. Selon Cordesse et al (1992) l'ingestion moyenne de 2 fourrages ( 1 foin de luzerne et une paille traitée par $\mathrm{NH}_{3}$ ) a été de $18,2 \mathrm{~g} / \mathrm{kg}$ PV pour les lamas et de $26,7 \mathrm{~g}$ pour les moutons. Des mesures faites par ailleurs sur un foin ordinaire (Jouany et Dulphy, données non publiées) donnent les valeurs respectives de $15,5 \mathrm{~g} /$ $\mathrm{kg}$ PV pour les lamas et $18,7 \mathrm{~g}$ pour les moutons. Au total, pour les 4 comparaisons citées, les valeurs moyennes sont donc de $16 \mathrm{~g} / \mathrm{kg}$ de PV pour les lamas et $21 \mathrm{~g}$ pour les moutons, soit 49 et $59 \mathrm{~g} / \mathrm{kg}$ $\mathrm{P} 0,75$.

\section{Équidés}

Dans une étude concernant 10 fourrages verts de bonne qualité, des chevaux à l'entretien ( $n=5, \mathrm{PV}=500 \mathrm{~kg}$ ) ont ingéré $19,8 \mathrm{~g} / \mathrm{kg}$ PV contre 26,4 pour les moutons ( $P V=55 \mathrm{~kg}$ ), à l'entretien également, soit 93,7 et $73,6 \mathrm{~g} / \mathrm{kg} \mathrm{P}^{0,75}$ respectivement (Chenost et Martin-Rosset, 1985). Les mêmes chevaux ont en revanche ingéré les mêmes quantités que des bovins $(P V=500 \mathrm{~kg})$. Par ailleurs Cymbaluk (1990), pour 8 fourrages secs, trouve aussi en moyenne le même niveau d'ingestion (22,4 g/kg PV) pour des chevaux que des bovins. Toutefois, les quantités ingérées (QI) des chevaux étaient très peu liées aux teneurs en lignocellulose (ADF), contrairement à ce qui est observé pour les bovins :

- chevaux: QI = 153-1,46 ADF $(r=0,52)$;

- bovins : $\mathrm{QI}=184$ - 2,35 ADF $(r=0,81)$;

( $Q$ l exprimées en g de MS/kg P0,75 et ADF exprimé en \% de la MS).

Pour des fourrages de qualité médiocre (ADF $=35 \%$ ), ces corrélations montrent que les chevaux ingèrent la même quantité que les bovins (102 g/kg PV0,75).

\section{Conclusion}

Avant de considérer les aptitudes d'une espèce à ingérer des fourrages, il est nécessaire de prendre en compte son poids vif et ses besoins. L'effet du poids vif est relativement faible sur les niveaux d'ingestion exprimés en $\mathrm{g} / \mathrm{kg}$ de $\mathrm{PV}$, mais il joue un rôle important par rapport à la couverture des besoins qui sont davantage corrélés au poids métabolique. Ainsi, les espèces animales les plus lourdes sont avantagées face à un fourrage offert à volonté, quelle que soit sa digestibilité. Les espèces légères seront alors obligées de choisir des fourrages plus digestibles pour couvrir leurs besoins.

La régulation de l'appétit des ruminants recevant des fourrages est de type "physique" avant tout (Balch et Campling, 1962), ce qui doit expliquer le faible effet du format, le volume maximal du rumen étant approximativement proportionnel au poids vif. Il semble cependant que des mécanismes particuliers soient mis en jeu pour permettre aux caprins et aux Cervidés d'ingérer plus de fourrages pauvres que les ovins, pour des poids vifs proches. 
Ces facteurs pourraient être, respectivement, un meilleur recyclage de l'azote (Tisserand et al, 1991) et peut-être un développement plus important du tube digestif pour les caprins et une durée de séjour plus réduite des aliments dans le tube digestif pour les Cervidés (Milne et al, 1978). La tendance pour les lamas à ingérer moins de fourrages que les ovins, en dépit de leur aptitude plus grande à recycler l'azote, pourrait être due à une meilleure utilisation de l'énergie (digestibilité supérieure, pertes en méthane plus faibles) ou à des besoins plus faibles.

Les quantités ingérées par les gros herbivores (bovins, dromadaires et chevaux) semblent tout à fait comparables. Le fait que les dromadaires recyclent mieux l'azote que les bovins devrait être un avantage à vérifier. Les chevaux étant moins sensibles à la teneur en parois des fourrages, ils ont probablement une capacité d'ingestion des fourrages peu digestibles supérieure à celle des bovins.

L'effet des besoins est très important. Lorsque ces besoins augmentent, avec la lactation par exemple, les quantités ingérées deviennent plus importantes chez toutes les espèces. On peut noter cependant que, souvent, ces augmentations d'ingestion ne suffisent pas à couvrir les besoins. Les animaux doivent alors en même temps recevoir des aliments plus digestibles pour être nourris correctement.

\section{DIGESTIBILITÉ DES FOURRAGES PAR LES DIFFÉRENTES ESPĖCES}

On dispose, dans la littérature, d'un nombre considérable de données sur la digestibilité des fourrages, car c'est le principal facteur d'estimation de leur valeur énergétique. Très souvent ces données ont été obtenues sur des moutons standard, en particulier lorsque l'objectif était de proposer aux éleveurs des Tables de la valeur nutritive des fourrages (cf INRA, 1988). Cependant le problème de l'extrapolation aux autres catégories de ruminants des données ainsi obtenues est posé depuis longtemps. Les résultats des travaux effectués pour répondre à ce problème permettent d'avoir une idée des variations de la digestibilité entre espèces.

\section{Ovins}

La digestibilité de la matière organique (dMO) des fourrages verts chez le mouton alimenté à volonté varie entre 55 et $85 \%$ (Demarquilly et Jarrige, 1981). Cette digestibilité diminue lorsque la teneur en cellulose brute augmente. La dMO des foins est plus faible que celle des fourrages verts initiaux et varie entre 50 et $80 \%$ (Andrieu et al, 1981). La digestibilité des pailles varie entre 40 et $50 \%$ selon l'espèce végétale, en fonction de la teneur en parois et de la lignification de ces parois.

Les variations de la teneur en parois et de leur digestibilité expliquent la majorité des variations de la digestibilité de la dMO. En effet, les glucides cytoplasmiques hydrosolubles des fourrages sont entièrement digestibles. La quantité de constituants non pariétaux apparemment non digestibles excrétée dans les fèces est peu variable : de l'ordre de $130 \mathrm{~g} / \mathrm{kg}$ de MS de fourrage ingéré (Jarrige, 1980). De même, la quantité de matières azotées excrétées dans les fèces (matières azotées non digestibles: MAND) par $\mathrm{kg}$ de MS ingérée est relativement constante (Demarquilly et al, 1978), autour de 40 à $50 \mathrm{~g} / \mathrm{kg}$ de MS.

Pratiquement toutes les mesures effectuées en France l'ont été avec des animaux nourris à volonté, pour obtenir en même temps l'ingestibilité des fourrages. Si les moutons sont nourris à l'entretien, la digestibilité augmente en moyenne de 1,6 point $(n=17)$ avec les fourrages verts (De- 
marquilly et Andrieu, 1987) et de 3,1 points $(n=13)$ avec les foins (Berge et Dulphy, 1991; Carle et Demarquilly, données non publiées). Ces différences s'expliquent en effet par un léger ralentissement de la vitesse de transit des digesta lorsque l'ingestion diminue.

Lorsqu'on apporte un aliment concentré, la digestibilité des parois du fourrage qui lui est associée est, en général, diminuée. On parle alors d'interactions digestives, dont les grands facteurs de variation ont été donnés par Berge et Dulphy (1991).

\section{Caprins}

D'après Devendra (1978), les premières études importantes sur les capacités digestives des caprins ont été faites en Inde (Mia et al, 1960), au Pakistan (Hossain, 1960) et au Canada (Byer et al, 1961). Ces études comparaient des chèvres à de jeunes bovins et montraient, sauf celles de Byer et al (1961), que les chèvres digéraient mieux la matière organique et surtout la cellulose brute des aliments étudiés. Devendra (1978) en concluait une supériorité digestive des caprins par rapport aux ovins et aux bovins, surtout pour les fourrages grossiers.

Une seconde synthèse concernant seulement les comparaisons caprins-ovins a donné des résultats beaucoup plus nuancés (Brown et Johnson, 1984). Sur 50 comparaisons, ces auteurs ne notent pas de différences significatives entre les 2 espèces animales et relèvent de nombreux problèmes de méthodologie expérimentale qui empêchent souvent les comparaisons d'être parfaitement rigoureuses.

En moyenne, la dMO est supérieure de seulement 1,1 point chez les caprins, ce qui est faible. Nous avons rassemblé les résultats de 23 publications par type d'aliments dans le tableau VI, ce qui repré- sente au total 128 comparaisons. En fait, les valeurs se dispersent de telle façon qu'on ne note pas d'avantage net avec les caprins, sauf pour 2 fourrages carencés en azote et non complémentés (Masson et al, 1986; Alam et al, 1985). Pour les pailles et les feuilles d'arbre, fourrages peu digestibles, la dMO est supérieure de seulement 2,1 points pour les caprins. Les caprins ne montreraient donc pas de supériorité sur les ovins, sauf peut-être avec les fourrages riches en parois (Tisserand et al, 1991), ce qui rejoint les conclusions de Morand-Fehr et Sauvant (1978).

Pour l'ensemble des résultats examinés (cf tableau VI), les relations entre les digestibilités chez les caprins et celles chez les ovins sont les suivantes :

$$
\begin{aligned}
& \mathrm{dMO}_{\text {cap }}=6,94+0,9032 \mathrm{dMO}_{\mathrm{ov}}(r=0,93) \\
& \mathrm{dMA}_{\text {cap }}=5,35+0,92 \mathrm{dMA}_{\mathrm{ov}}(r=0,97) \\
& \mathrm{dCB}_{\text {cap }}=10,4+0,849 \mathrm{dCB}_{\mathrm{ov}}(r=0,93)
\end{aligned}
$$

D'après ces relations, pour une digestibilité égale à 40 chez les ovins, les valeurs $\mathrm{dMO}, \mathrm{dMA}$ et dCB sont supérieures respectivement de $3,1,2,1$ et 4,4 chez les caprins. II y a égalité des valeurs chez les 2 espèces pour $\mathrm{dMO}=72 \mathrm{dMA}=67$ et $\mathrm{dCB}=69$.

Finalement, le très léger avantage des caprins provient donc du fait qu'ils digèrent un peu mieux les parois, représentées ici par la cellulose brute $(+1,3$ point, différence non significative). Cet avantage est net pour une majorité d'aliments, sauf pour les ensilages de maïs et les fourrages verts. Parmi les causes qui pourraient expliquer ce très léger avantage des caprins, une tendance à trier davantage à l'auge que les ovins est souvent citée (MorandFehr et al, 1980; Giger et al, 1987). Ce phénomène n'est peut-être pas négligeable, bien que les auteurs aient en général tenté de le limiter en ne tolérant qu'un pourcentage de refus restreint. 
Tableau VI. Digestibilités comparées entre ovins et caprins (\%).

\begin{tabular}{|c|c|c|c|c|c|c|c|}
\hline \multirow[t]{2}{*}{ Nature du régime } & \multirow{2}{*}{$\begin{array}{l}\text { Nb de } \\
\text { réf }\end{array}$} & \multicolumn{2}{|c|}{ Digestibilité de la MO } & \multicolumn{2}{|c|}{ Digestibilité de la $C B$} & \multicolumn{2}{|c|}{ Digestibilité de la MAT } \\
\hline & & Ovins & Caprins & Ovins & Caprins & Ovins & Caprins \\
\hline Concentrés & 4 & \multicolumn{2}{|c|}{$(10)^{74,7}$} & \multicolumn{2}{|c|}{$(10)$} & 77,4 & 77,6 \\
\hline Ensilages de maïs & 2 & \multicolumn{2}{|c|}{ (7) } & \multicolumn{2}{|c|}{ (7) } & \multicolumn{2}{|c|}{$(7)$} \\
\hline Fourrages verts & 3 & \multicolumn{2}{|c|}{ (17) } & \multicolumn{2}{|c|}{ (17) } & \multicolumn{2}{|l|}{ 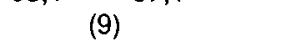 } \\
\hline Ensilages d'herbe & 4 & \multicolumn{2}{|c|}{${ }_{(15)}^{68,5}$} & \multicolumn{2}{|c|}{${ }_{(10)}^{71,9}$} & \multicolumn{2}{|c|}{ (10) } \\
\hline Foins & 16 & \multicolumn{2}{|c|}{ (56) } & \multicolumn{2}{|c|}{ (42) } & 57,7 & 57,9 \\
\hline Fourrages pauvres & 7 & \multicolumn{2}{|c|}{ (13) } & \multicolumn{2}{|c|}{ (12) } & \\
\hline Feuilles d'arbre & 4 & \multicolumn{2}{|c|}{$(10)^{34,0}$} & \multicolumn{2}{|c|}{ (6) } & \multicolumn{2}{|c|}{ (5) } \\
\hline Ensemble & 23 & 62,9 & 64,0 & 57,0 & 58,3 & 62,5 & 62,7 \\
\hline
\end{tabular}

Entre parenthèses : nombre de comparaisons. Références : celles du tableau II et Baumgardt et al, 1964. El Hag, 1976 ; Huston et al, 1986 ; Alam et al, 1987 ; Howe et al, 1988 ; McCabe et Barry, 1988. NS : différence non significative $\{P<0,05)$.

\section{Bovins}

Les premières comparaisons entre ovins et bovins sont relativement anciennes puisque Cipolloni et al (1951) citent déjà des résultats pour 27 aliments avec de nombreuses répétitions, certaines publications remontant à 1904. Parmi les travaux anciens, on peut citer aussi ceux de Forbes et Garrigus (1950), Swift et Bratzler (1959), Alexander et al (1962), Van Dyne et Lofgreen (1964). Des synthèses ont èté ensuite publiées par Playne (1978), Van
Soest (1980), Chenost et Martin-Rosset (1985). Par ailleurs, certains auteurs ont publié chacun un nombre considérable de comparaisons (31 par Engels et al, 1978 ; 28 par Vona et al, 1984 ; 82 par Aerts et al, 1984 ; 153 par Reid et al, 1990).

Selon les cas, les auteurs ont utilisé des jeunes bovins (surtout des bouvillons de $300 \mathrm{~kg}$ environ, parfois des taurillons ou des génisses) ou des vaches adultes dans différentes situations physiologiques. II semble que l'état des moutons témoins ait été moins variable, mais leurs races étaient différentes. 
Tableau VIl. Digestibilités comparées entre ovins et bovins (\%).

\begin{tabular}{|c|c|c|c|c|c|c|c|}
\hline \multirow[t]{2}{*}{ Nature du régime } & \multirow{2}{*}{$\begin{array}{l}\text { Nb de } \\
\text { réf }\end{array}$} & \multicolumn{2}{|c|}{ Digestibilité de la $M O$} & \multicolumn{2}{|c|}{ Digestibilité de la $C B$} & \multicolumn{2}{|c|}{ Digestibilité de la MAT } \\
\hline & & Ovins & Bovins & Ovins & Bovins & Ovins & Bovins \\
\hline Concentrés & 5 & \multicolumn{2}{|c|}{$\begin{array}{c}79,1 \quad 76,8 \\
(20) N S\end{array}$} & \multicolumn{2}{|c|}{$46,4{ }_{(14)}^{39,8}$} & \multicolumn{2}{|l|}{12,0} \\
\hline Ensilages de maïs & 3 & \multicolumn{2}{|c|}{ (22) NS } & \multicolumn{2}{|c|}{ (14) } & \multicolumn{2}{|c|}{ (22) } \\
\hline Fourrages verts & 4 & \multicolumn{2}{|c|}{ (27) NS } & - & - & - & - \\
\hline Ensilages d'herbe & 2 & \multicolumn{2}{|c|}{ (14) NS } & \multicolumn{2}{|c|}{${ }_{(14)}^{16,0}$} & \multicolumn{2}{|c|}{ (14) } \\
\hline Foins & 20 & \multicolumn{2}{|c|}{$\begin{array}{c}59,0 \quad{ }^{62,7} \\
(98) S^{-1}\end{array}$} & \multicolumn{2}{|c|}{${ }_{(76)}^{59,7}$} & \multicolumn{2}{|c|}{$(64)$} \\
\hline Fourrages pauvres & 12 & \multicolumn{2}{|c|}{${ }_{\text {(24) } \mathrm{S}^{46,8}}^{51,8}$} & \multicolumn{2}{|c|}{ (7) } & 34,4 & 29,0 \\
\hline Ensemble & 32 & $\begin{array}{l}62,0 \\
(20\end{array}$ & $S^{64,4}$ & $\begin{array}{l}59,3 \\
\quad 12\end{array}$ & $S^{62,3}$ & $\begin{array}{r}60,3 \\
\quad(11\end{array}$ & $\begin{array}{l}59,3 \\
\text { NS }\end{array}$ \\
\hline
\end{tabular}

Entre parenthèses : nombre de comparaisons. $S$ : différence significative $(P<0,05)$. Références : Swift et Bratzler, 1959 ; Blaxter et Wainman, 1961 ; Samsher et Majmudar, 1962 ; Buchman et Hemken, 1964 ; Van der Noot et al, 1965 ; Blaxter et al, 1966 ; Cameron, 1966; Donefer, 1966 ; Hintz, 1969 ; Leaver et al, 1969 ; Colovos et al, 1970 ; Playne, 1970 ; Johnsson, 1972 ; Siebert et Kennedy, 1972 ; Wilkins et al, 1972 ; Greenhalgh et Reid, 1973 ; Bird, 1974 ; Arman et Hopcraft, 1975 ; Thomas et Campling, 1977 ; Blaxter et Boyne, 1978 ; Engels et al, 1978; Playne, 1978 ; Poppi et al, 1980 ; Rees et Little, 1980 ; Horton et al, 1981 ; Van Rooyen et Van Der Merwe, 1983 ; Aerts et al, 1984 ; Prigge et al, 1984 ; Vona et al, 1984 ; Bines et al, 1988 ; Dulphy et al, 1990a.

Bien que les animaux adultes digèrent légèrement mieux que les jeunes $(0$ à 3 points selon les auteurs; McArthur, 1957 ; Buchman et Hemken, 1964 ; Jentsch et al, 1988 ; Dulphy et al, 1990a), les résultats récapitulés dans le tableau VII n'ont pas été triés pour tenir compte de l'âge des animaux. Ces résultats ne sont pas exhaustifs; ils concernent 205 comparaisons, dans lesquelles les aliments étaient répartis en 6 classes. D'après ces résultats, les bovins ont une digestibilité légèrement supérieure à celle des ovins $(+2,4$ points pour la MO), avec des écarts variables selon les classes d'aliments.

Les fourrages riches en parois sont nettement mieux digérés par les bovins (Playne, 1978 ; Van Soest, 1980). L'écart entre espèces animales atteint 5 points pour les fourrages pauvres. À l'inverse, les écarts deviennent nuls lorsque la digestibilité de ces fourrages est proche de $70 \%$ (cas des ensilages). Ils sont également plus faibles pour les Légumineuses que les Graminées. En revanche, les bovins digèrent souvent moins bien les aliments 
concentrés. Les ensilages de maïs, composés en fait de près de $50 \%$ de grains, sont digérés un peu moins bien par les bovins.

Les différences observées au niveau de la dMO s'expliquent d'abord par une digestibilité supérieure des parois végétales par les bovins : +3 points en moyenne pour la cellulose brute, cet écart étant indépendant du fourrage. Les conséquences sur la $\mathrm{dMO}$ sont donc plus importantes pour les fourrages riches en parois, ce qui va souvent de pair avec une faible digestibilité de ces fourrages. En revanche, la quantité de matière organique fécale d'origine métabolique (débris microbiens, endogène) est plus élevée chez les bovins (Van Soest, 1980 ), ce qui peut contribuer à réduire les écarts pour les fourrages très digestibles. De plus, l'amidon, en particulier celui des ensilages de maïs, est moins digestible chez les bovins (Carle et Dulphy, données non publiées).

Les digestibilités sont souvent mesurées avec des animaux alimentés au niveau de l'entretien. Lorsque ces animaux sont alimentés à volonté, les écarts de digestibilité observés peuvent se modifier. En effet, la sensibilité au niveau d'alimentation semble être plus élevée chez les ovins (tableau VIII). Le phénomène est même accentué en présence d'aliment concentré. Les écarts de digestibilité entre ovins et bovins peuvent donc varier avec la nature et le niveau d'alimentation du régime distribué. Ainsi, entre une distribution d'aliment au niveau de l'entretien et à volonté, la supériorité de la digestibilité chez les vaches, par rapport aux moutons, passe de 3,4 points à 5,2 points. Prigge et al (1984) trouvent des résultats comparables : +1 point en quantité limitée, mais

Tableau VIII. Influence du niveau d'alimentation sur la digestibilité (\%) pour différents types d'animaux. Moyenne de 4 fourrages (Carle et Dulphy, résultats non publiés).

\begin{tabular}{|c|c|c|c|c|c|}
\hline $\begin{array}{l}\text { Mode de distribution du fourrage } \\
\text { (poids vif } \mathrm{kg} \text { ) }\end{array}$ & $\begin{array}{l}\text { Moutons } \\
\text { (66) }\end{array}$ & $\begin{array}{l}\text { Brebis } \\
(56)\end{array}$ & $\begin{array}{l}\text { Chèvres } \\
\text { (47) }\end{array}$ & $\begin{array}{l}\text { Taurillons } \\
\text { (356) }\end{array}$ & $\begin{array}{l}\text { Vaches } \\
\text { (557) }\end{array}$ \\
\hline \multicolumn{6}{|l|}{ Seul limité à l'entretien } \\
\hline $\mathrm{dMO}^{1}$ & 71,6 & 72,7 & 70,0 & 73,2 & 75,0 \\
\hline$d_{C B}{ }^{2}$ & 69,4 & 70,3 & 66,8 & 75,8 & 77,6 \\
\hline \multicolumn{6}{|l|}{ Seul à volonté } \\
\hline $\mathrm{dMO}$ & 67,3 & 69,7 & 68,1 & 71,0 & 72,5 \\
\hline $\mathrm{dCB}$ & 68,2 & 69,6 & 67,6 & 73,9 & 73,6 \\
\hline \multicolumn{6}{|l|}{$+30 \%$ concentré à volonté } \\
\hline $\mathrm{dMO}$ & 70,2 & 73,0 & 71,8 & 72,4 & 74,4 \\
\hline $\mathrm{dCB}$ & 60,4 & 64,4 & 63,2 & 69,0 & 68,0 \\
\hline \multicolumn{6}{|l|}{$+30 \%$ concentré limité à l'entretien } \\
\hline $\mathrm{dMO}$ & 72,0 & 74,5 & 73,9 & 73,0 & 75,8 \\
\hline dCB & 64,0 & 66,0 & 64,3 & 70,0 & 71,1 \\
\hline
\end{tabular}

${ }^{1} \mathrm{dMO}$ : digestibilité de la matière organique $;^{2} \mathrm{dCB}$ : digestibilité de la cellulose brute. 
+6 points, à volonté, en faveur des bouvillons.

Pour les matières azotées, il y a une tendance, dans les résultats examinés (tableau VII), à ce que la digestibilité soit inférieure chez les bovins ( -1 point). Cela est plus net pour les aliments riches en MAT ou lorsque la digestibilité de ces MAT dépasse $55 \%$. La cause pourrait être recherchée dans les pertes fécales plus élevées signalées plus haut et/ou à un rôle digestif plus important du gros intestin chez les bovins. Schiemann et al (1968) avaient déjà noté une digestibilité apparente des MAT supérieure de 4 points chez les ovins. Prigge et al (1984) ont aussi noté cette tendance. À l'inverse, ces auteurs constatent plus de pertes urinaires chez les ovins.

\section{Cervidés}

D'après les résultats de Maloiy et al (1968), Kay et Goodall (1976), Milne et al (1978) et Huston et al (1986), la digestibilité d'une même ration est, à l'exception de la bruyère, toujours plus faible chez le cerf que le mouton : baisse moyenne de 3,5 points pour 26 comparaisons, l'écart trouvé étant indépendant de la digestibilité. Bien qu'il y ait peu de résultats disponibles, il semble que la situation soit plus contrastée avec les fourrages peu digestibles. L'écart en faveur des ovins est plus élevé pour 3 d'entre eux, mais la supériorité des cerfs apparaît nettement avec la bruyère. II est probable que cette plante contienne des composés que les ovins ne peuvent pas digérer. Malgré les travaux effectués, des comparaisons restent cependant à faire pour situer plus précisément les 2 espèces l'une par rapport à l'autre dans des conditions comparables. Cela est d'autant plus nécessaire que, avec de jeunes animaux, Fennessy et al
(1980) trouvent une supériorité des cerfs à digérer à la fois des pellets très digestibles et un mauvais foin de Graminées.

\section{Camélidés}

Il y a eu très peu de mesures faites que ce soit sur les gros Camélidés (dromadaires) ou sur les petits (lamas).

Si on regroupe les mesures de Gihad et al (1989), Farid et al (1979) et Kayouli et al (1992), on trouve, pour 5 régimes différents, une dMO moyenne de 56,2\% chez les dromadaires et 52,4 chez les ovins. De la même façon, le regroupement des résultats de Hintz et al (1973), Warmington et al (1989) et de Cordesse et al (1992) donne, pour 5 régimes également, une dMO moyenne de $64,3 \%$ chez les lamas contre 61,0 chez les moutons.

Pour les matières azotées, la différence de digestibilité entre les Camélidés et les ruminants serait négligeable d'après $\mathrm{Ma}$ loiy (1972), Farid et al (1985), Gihad et al (1989), Cordesse et al (1992), Kayouli et al (1993). En revanche, Hintz et al (1973) ont trouvé que la digestibilité de l'azote était légèrement plus élevée de 5-6 points chez les lamas que chez les ovins.

Les écarts observés au niveau de la MS et de la MO proviennent surtout d'une meilleure digestibilité des parois végétales: $+8,7$ points en moyenne en faveur des dromadaires (5 comparaisons) et $+7,4$ points en faveur des lamas (3 comparaisons). Si ces écarts se confirmaient, les Camélidés digéreraient donc mieux les parois végétales que les bovins.

\section{Équidés}

Martin-Rosset et al (1984) ont comparé la digestibilité de 33 fourrages chez le cheval et le mouton. Dans ces comparaisons, la 
dMO chez le cheval a été, en moyenne, inférieure de 4 points à celle mesurée chez le mouton. Les écarts sont plus importants pour les Graminées et les pailles $(5,1$ points) que pour les Légumineuses $(2,4$ points) qui se digèrent rapidement. Par ailleurs, les écarts entre le cheval et le mouton sont d'autant plus importants que les fourrages ont une digestibilité faible. Ils atteignent 8 points pour les pailles.

Plus récemment, Cymbaluk (1990) a trouvé, pour 6 foins de Graminées, des écarts de 12,6 points chez des chevaux par rapport à des bovins (dMS respectivement égales à 44,6 et $57,2 \%$ pour les chevaux et les bovins; dNDF égales à 44,0 et $60,5 \%$ ). Enfin, Smolders et al (1990) ont mesuré des dMO inférieures de 8 points chez les chevaux par rapport à des moutons avec des fourrages verts ou secs de Graminées, mais les moutons étaient alimentés au niveau de l'entretien, ce qui augmente les écarts par rapport à ceux alimentés à volonté.

Le niveau d'alimentation ne modifierait pas, contrairement à ce qui se passe chez les ruminants (Berge et Dulphy, 1991), la digestibilité chez le cheval (Martin-Rosset et al, 1990), probablement parce que la vitesse de transit des digesta n'est pas modifiée (Miraglia et al, 1994). À l'entretien, les écarts de digestibilité entre chevaux et ruminants s'accentuent donc (MartinRosset et Dulphy, 1987). Par ailleurs, lorsqu'on ajoute au fourrage un aliment concentré riche en amidon, ce concentré ne modifie pas la digestibilité du fourrage par les chevaux (Martin-Rosset et Dulphy, 1987). En effet, l'amidon et les glucides solubles sont essentiellement digérés dans l'intestin grêle (70 à $95 \%$; Hintz et al, 1971 ; Wolter et Chaabouni, 1979 ; MartinRosset et al, 1987).

Il est donc clair que la digestibilité des fourrages est plus faible chez les Équidés que chez les ruminants (cf Van Soest,
1982). Cependant, il peut exister des différences entre les espèces d'Equidés, la digestibilité chez les ânes par exemple étant un peu plus élevée que celle des poneys (Tisserand, données non publiées). En revanche, les différences mesurées entre chevaux et poneys semblent faibles (Slade et Hintz, 1969 ; Foose, 1982 ; Uden et Van Soest, 1982 ; Hoffman et al, 1987 ; Cymbaluk et al, 1989; Martin-Rosset et Vermorel, résultats non publiés). Elles ne sont pas significatives non plus entre chevaux de race lourde et légère (Martin-Rosset et al, 1990). Le nombre de comparaisons entre chevaux et moutons demeure cependant un peu faible, et mériterait d'être augmenté.

La digestibilité plus faible des fourrages chez le cheval résulte essentiellement d'une moins bonne digestion des parois végétales : la digestibilité de la cellulose brute est inférieure de 9,9 points pour les Graminées et de 5,5 points pour les Légumineuses dans les essais de MartinRosset et al (1984). La digestibilité des parois (NDF) est inférieure de 16,5 points pour les 6 foins de Graminées étudiés par Cymbaluk (1990), et de 5 à 15 points selon Van Der Noot et Gilbreath (1970), les comparaisons dans les 2 cas étaient effectuées avec des bovins.

La digestibilité des MAT semble en revanche tout à fait comparable entre les chevaux et les bovins (Hintz, 1969 ; Van der Noot et Gilbreath, 1970 ; Cymbaluk, 1990). De la même façon, Martin-Rosset et al (1984) ont trouvé des teneurs en matières azotées non digestibles (MAND) tout à fait identiques pour les chevaux et les moutons (40 à $50 \mathrm{~g} / \mathrm{kg} \mathrm{MS}$ ). Enfin, Slade et Robinson (1970) considèrent que les MAND chez le cheval sont égales à $33+$ 0,2 MAT (MAND et MAT en $\mathrm{g} / \mathrm{kg}$ de MS), valeur qui est proche de celle trouvée par Demarquilly et al (1978) pour des foins de Graminées distribués à des moutons $(36+$ 0,11 MAT). 


\section{Discussion des résultats de digestibilité}

Malgré des résultats souvent comparables, en particulier pour les fourrages dont la dMO est supérieure à $60 \%$, il existe, entre les 6 espèces d'herbivores étudiées, quelques différences intéressantes à relever.

Les caprins présentent, par rapport aux ovins, un certain avantage pour les fourrages pauvres. D'après Tisserand et al (1991), il y aurait à cela 3 causes principales : un temps de séjour plus long dans le tube digestif, une concentration en microbes cellulolytiques plus élevée dans le rumen et un meilleur recyclage de l'azote.

Les bovins, malgré une réduction des aliments ingérés en particules plus grossières que celles observées chez les ovins (Grenet, 1966 et 1970), digèrent mieux les parois végétales grâce à un temps de séjour plus long des digesta dans leur tube digestif (Carle et Dulphy, 1980). Cela est d'autant plus net que les fourrages concernés sont riches en parois.

Les Cervidés, à cause probablement d'un transit des digesta plus rapide que celui des ovins, ont tendance à digérer moins bien les fourrages, à l'exception surprenante de la bruyère. Une hypothèse avancée pour expliquer cette observation serait la capacité de ces animaux à inhiber l'action des tannins, ou d'autres composés antinutritionnels, dont sont riches ces plantes.

Les Camélidés sont des animaux adaptés à des conditions difficiles. On observe en effet qu'ils digèrent mieux les fourrages que les ovins. Leurs aptitudes seraient donc proches de celles des bovins, à la fois à cause d'un recyclage très efficace de l'azote et des minéraux (Engelhardt et al, 1986) et d'un temps de séjour des aliments plus long dans le tube digestif (Kayouli et al, 1993). Ces mécanismes permettent une meilleure activité des bactéries cellulolytiques (Kayouli et al, 1991 et 1993). Les conditions régnant dans le compartiment 1 sont plus favorables chez les Camélidés, puisque l'absorption des AGV serait plus rapide que chez les ovins (Engelhardt et Höller, 1982) et le milieu ruminal est mieux tamponné (Kayouli et al, 1992).

Les Équidés enfin, en particulier les chevaux, digèrent moins bien les parois végétales et donc les fourrages, que les ruminants. Cependant, si l'on compare l'énergie nette qu'ils retirent de ces aliments, on constate qu'ils sont plus efficaces pour les fourrages peu ou moyennement riches en parois, à cause de pertes en méthane 2 à 3 fois plus faibles lors de la digestion (Vermorel et al, 1984). En revanche, cet avantage ne compense pas la très faible digestibilité des pailles. Ainsi, les valeurs énergétiques nettes de l'orge, d'un bon foin et d'une paille sont respectivement de $2200 \mathrm{kcal} / \mathrm{kg} \mathrm{MS}, 1342$ et 572 chez les chevaux contre 1700,1207 et 714 chez les ovins.

\section{CONCLUSION}

$\grave{A}$ l'auge, dans des conditions identiques, il y a donc des différences entre les espèces d'herbivores quant à leurs aptitudes à ingérer et à digérer des fourrages. Ces différences sont d'autant plus nettes que les fourrages sont riches en parois végétales et pauvres en azote. Dans ce dernier cas, les bovins sont les plus avantagés et, à un degré moindre, les caprins et les Camélidés. Les chevaux, dans la mesure où ils peuvent maintenir un niveau d'ingestion élevé lié à l'absence de dispositif anatomique efficace retenant longtemps les aliments au niveau du gros intestin, pourraient compenser une faible digestibilité par un niveau d'ingestion supérieur. 
Dans des conditions "naturelles", ces différences peuvent être en partie compensées par les possibilités d'adaptation de l'animal à son milieu. Ainsi, des animaux tels que les caprins, les Cervidés et, dans une certaine mesure, les Camélidés, sont des animaux beaucoup plus aptes à choisir des aliments digestibles grâce à leur comportement de sélectivité ou à leur agiletè. $\dot{A}$ l'inverse, les chevaux et surtout les bovins sont peu sélectifs à l'extérieur.

Enfin, quelques adaptations physiologiques sont intéressantes à souligner : un transit lent des digesta pour les bovins, une taille maximale du rumen élevée pour les ovins et les bovins, un recyclage efficace des minéraux et de l'azote pour les caprins et les Camélidés, peu de pertes de méthane lors de la digestion des parois pour les Équidés. Ces adaptations n'ont pas été développées ici, mais leur connaissance est fondamentale.

\section{RÉFÉRENCES}

Aerts JV, De Boever JL, Cottyn BG, De Brabander DL, Buysse FX (1984) Comparative digestibility of feedstuffs by sheep and cows. Anim Feed Sci Technol 12, 47-56

Agabriel J, Dulphy JP, Micol D (1987) Utilisation des foins pour la croissance et l'engraissement des bovins. In: Les fourrages secs, récolte, traitement, utilisation (C Demarquilly, ed) INRA, Paris, 283-318

Alam MR, Lawson GD, Poppi DP, Sykes AR (1987) Comparison of the site and extent of digestion of nutrients of a forage in kids and lambs. J Agric Sci Camb 109, 583-589

Alam MR, Poppi DP, Sykes AR (1983) Intake, digestibility and retention time of 2 forages by kids and lambs. Proc N Z Soc Anim Prod 43, 119-121

Alam MR, Poppi DP, Sykes AR (1985) Comparative intake of digestible organic matter and water by sheep and goats. Proc N Z Soc Anim Prod 45, 107-111

Alexander RA, Hentges JF Jr, McCall JT, Ash WO (1962) Comparative digestibility of nu- trients in roughages by cattle and sheep. J Anim Sci 21, 373-376

Andrieu J, Demarquilly C, Wegat-Litre E, Weiss $P$ (1981) Prévision de la valeur énergétique des foins. In: Prévision de la valeur nutritive des aliments des ruminants. INRA, Versailles, 119-128

Andrieu J, Demarquilly C (1987) Composition et valeur alimentaire des foins et des pailles. In : Les fourrages secs : récolte, traitement, utilisation (C Demarquilly, ed). INRA, Paris, 163-182

Antoniou T, Hadjipanayiotou M (1985) The digestibility by sheep and goats of five roughages offered alone or with concentrates. $J$ Agric Sci Camb 105, 663-671

Arman P, Hopcraft D (1975) Nutritional studies on East African herbivores. 1. Digestibilities of dry matter, crude fibre and crude protein in antelope, cattle and sheep. Br J Nutr 33, 255-264

Balch CC, Campling RC (1962) Regulation of voluntary food intake in ruminants. Nutr Abstr Rev 32, 669-686

Baumgardt BR, Byer WJ, Jumah HF, Krueger CR (1964) Digestion in the steer, goat and artificial rumen as measures of forage nutritive value. J Dairy Sci 47, 160-164

Berge P, Dulphy JP (1991) Étude des interactions entre fourrage et aliment concentré chez le mouton. II. Facteurs de variation de la digestibilité. Ann Zootech 40, 227-246

Bines JA, Broster WH, Sutton JD et al (1988) Effect of amount consumed and diet composition on the apparent digestibility of feed in cattle and sheep. J Agric Sci Camb 110, 249259

Bird PR (1974) Sulphur metabolism and excretion studies in ruminants. XIII. Intake and utilization of wheat straw by sheep and cattle. Austr J Agric Res 25, 631-642

Blanchard G, Brun-Bellut J, Vignon B (1980) Comparaison des caprins aux ovins quant à l'ingestion, la digestibilité et la valeur alimentaire des diverses rations. Reprod Nutr Dev 20 (5B), 1731-1737

Blaxter KL, Wainman FW (1961) The utilization of food by sheep and cattle. J Agric Sci 57, 419-425

Blaxter KL, Wainman FN, Davidson JL (1966) The voluntary intake of food by sheep and 
cattle in relation to their energy requirements for maintenance. Anim Prod 8, 75-83

Blaxter KL, Boyne AW (1978) The estimation of the nutritive value of feeds as energy sources for ruminants and the derivation of feeding systems. J Agric Sci 90, 47-68

Bocquier $F$, Thériez $M$, Prache $S$, Brelurut $A$ (1988) Alimentation des ovins. In: Alimentation des bovins, ovins et caprins. INRA, Paris, 249-281

Brown LE, Johnson WL (1984) Comparative intake and digestibility of forages and byproducts by goats and sheep: a review. Int Goat Sheep Res 2(3), 212-226

Brown LE, Johnson WL (1985) Intake and digestibility of wheat straw diets by goats and sheep. J Anim Sci 60, 5, 1318-1323

Buchman DT, Hemken RW (1964) Ad libitum intake and digestibility of several alfalfa hays by cattle and sheep. J Dairy Sci 47, 861-864

Byer WJ, Jumah HF, Baumgardt BR, Niedermerer RP (1961) Digestion in the steer, goat and artificial rumen as measure of the nutritive value of alfalfa harvested at four stages of maturity. J Dairy Sci 44, 1173 (abstr)

Cameron CDT (1966) The effect of nitrogen fertilizer application rates to grass on forage yields, body weight gains feed utilization and vitamin A status of steers. Can J Anim Sci 46, 19-23

Carle B, Dulphy JP (1980) Comportement alimentaire comparé des ovins et des bovins. Relation avec la digestion des aliments. Reprod Nutr Dev 20 (5B), 1633-1639

Chenost M (1972) Observations préliminaires sur la comparaison du potentiel digestif et de l'appétit des caprins et des ovins en zone tropicale et en zone tempérée. Ann Zootech 21 (1), 107-111

Chenost M, Martin-Rosset W (1985) Comparaison entre espèces (mouton, cheval, bovin) de la digestibilité et des quantités ingérées des fourrages verts. Ann Zootech 34, 291-312

Cipolloni MA, Schneider BH, Lucas HL, Pavlech HM (1951) Significance of the differences in digestibility of feeds by cattle and sheep. $J$ Anim Sci 10, 337-343

Colovos NF, Holter JB, Koes RM, Urban WE Jr, Davis HA (1970) Digestibility, nutritive value and intake of ensiled corn plant (zea mays) in cattle and sheep. J Anim Sci 819-824
Cordesse R, Inesta M, Gaubert JL (1992) Intake and digestibility of four forages by llamas and sheep. Ann Zootech 41, 91-92

Cymbaluk NF (1990) Comparison of forage digestion by cattle and horses. Can J Anim Sci 70, 601-610

Cymbaluk NF, Christison GI, Leach DH (1989) Nutrient utilization by limit and ad libitum fed growing horses. J Anim Sci 67, 414-425

Demarquilly C, Andrieu J, Sauvant D, Dulphy JP (1978) Composition et valeur nutritive des aliments. In: Alimentation des ruminants, INRA, Versaillles, 469-518

Demarquilly C, Andrieu J, Weiss P (1981) L'ingestibilité des fourrages verts et des foins et sa prévision. In: Prévision de la valeur nutritive des aliments des ruminants. INRA, Versailles, 155-167

Demarquilly C, Jarrige R (1981) Panorama des méthodes de prévision de la digestibilité et de la valeur énergétique des fourrages. In: Prévision de la valeur nutritive des aliments des ruminants. INRA, Versailles, 41-60

Demarquilly C, Andrieu J (1987) Digestibilité et ingestibilité des fourrages verts chez le mouton : effets respectifs du niveau d'alimentation et de l'âge ou du poids des animaux. Reprod Nutr Dev 27 (18), 281-282

Devendra C (1978) The digestive efficiency of goats. World Rev Anim Prod XIV , 1, 9-22

Donefer $E$ (1966) Collaborative in vivo studies on alfalfa hay. J Anim Sci 25, 1227-1231

Doyle PT, Egan JK, Thalen AJ (1984) Intake, digestion and nitrogen and sulfur retention in Angora goats and Merino sheep fed herbage diets. Aust J Exp Agric Anim Husb 24, 165169

Dulphy JP, Faverdin P, Micol D, Bocquier F (1987) Révision du système des unités d'encombrement. Bull Tech CRZV Theix, INRA, 70, 35-48

Dulphy JP, Carle B, Demarquilly C (1990a) Quantités ingérées et activités alimentaires comparées des ovins, bovins et caprins recevant des fourrages conservés avec ou sans aliment concentré. I. Étude descriptive. Ann Zootech 39, 95-111

Dulphy JP, Jailler $M$, Jamot $J$, Bousquet $H$ (1990b) Amélioration de la prévision de la valeur alimentaire de certains foins au laboratoire. Fourrages 121, 65-78 
El Hag CA (1976) A comparative study between desert goat and sheep efficiency of feed utilization. World Rev Anim Prod 12, 43-48

Engelhardt WV, Höller H (1982) Salivary and gastric physiology of camelids. Verh Dtsch Zool Ges 195-204

Engelhardt WV, Lechner-Doll $M$, Heller $R$, Schwartz HJ, Rutagwenda T, Schultka W (1986) Physiology of the forestomach in camelids with particular reference to adaptation to extreme dietary conditions. A comparative approach. Zool Beitr NF 30, 1-15

Engels EAN, Ferreira B, Swart JA, Nieman PJ (1978) Comparative feed intake and digestibility studies with sheep and cattle on roughages. S Afric J Anim Sci 8, 149-152

Farid MFA, Shawket SM, Abdel Rahman MHA (1979) The nutrition of camels and sheep under stress. In: The camelid, an all-purpose animal ( $W$ Ross Cockrill, ed) Vol 1, Proc Khartoum workshop on camels, dec, 293-322

Farid MFA, Sooud AO, Hassan NI (1985) Effect of type of diet and level of protein intake on feed utilization in camels and sheep. Proc of the 3rd AAP Animal Sci Congress, 6-10 May, vol 2, 781-783

Faverdin P, Hoden A, Coulon JB (1987) Recommandations alimentaires pour les vaches laitières. Bull Tech CRZV Theix INRA, 70, 133152

Fennessy PF, Greer GJ, Forss DA (1980) Voluntary intake and digestion in red deer and sheep. Proc NZ Soc Anim Prod 40, 158162

Focant M (1984) Comportement alimentaire, rumination, fermentations réticulo-ruminales et acides gras volatils plasmatiques, comparés chez la chèvre et le mouton; influence du régime. Reprod Nutr Dev 24 (3), 239-250

Foose TJ (1982) Trophic strategies of ruminant versus non-ruminant ungulates. $\mathrm{PhD}$ Thesis, Chicago University, $337 p$

Forbes RM, Garrigus WP (1950) Sorne effects of forage composition on its nutritive value when cut and fed green to steers and wethers, as determined conventionally and by the lignin ratio. J Anim Sci 9, 531-539

Geoffroy $F$ (1974) Étude comparée du comportement alimentaire et mérycique de deux petits ruminants : la chèvre et le mouton. Ann Zootech 23, 63-73
Giger S, Sauvant D, Hervieu J, Dorléans M (1987) Valeur alimentaire du foin de luzerne pour la chèvre. Ann Zootech 36, 139-152

Gihad EA (1976) Intake, digestibility and nitrogen utilization of tropical natural grass hay by goats and sheep. J Anim Sci 43, 4, 879-883

Gihad EA, El Bedawy TM, Mehrez AZ (1980) Fiber digestibility by goats and sheep. J Dairy Sci 63, 1701-1706

Gihad EA, El Gallad TT, Sooud AE, Abdou EI Nasr HM, Farid MFA (1989) Feed and water intake, digestibility and nitrogen utilization by camels compared to sheep and goats fed low protein desert by-products. In: Options méditerranéennes, Série Séminaires $n^{\circ} 2,75-81$

Greenhalgh JFD, Reid GW (1973) The effect of pelleting various diets on intake and digestibility in sheep and cattle. Anim Prod 16, 223233

Grenet E (1966) Les particules végétales des fèces de mouton. Ann Zootech 15(4), 303312

Grenet E (1970) Taille et structure des particules végétales au niveau du feuillet et des fèces chez les bovins. Ann Biol Anim Biochim Biophys 10(4), 643-657

Hintz HF (1969) Review article: equine nutrition. Comparisons of digestion coefficients obtained with cattle, sheep, rabbits and horses. The Veterinarian 6, 45-51

Hintz HF, Argenzio RA, Schryver HF (1971) Apparent digestion in various segments of digestive tract of ponies fed diets with varying roughage-grain ratios. J Anim Sci 32, 245248

Hintz HF, Schryver HF, Halbert M (1973) A note on the comparison of digestion by new world camels, sheep and ponies. Anim Prod 16, 303-305

Hoffman M, Steinhöfel O, Fuchs R (1987) Untersuchungen zur Verdaulichkeit der Rohnährstoffe bei Pferden. Arch Anim Nutr 37, 351362

Horton GMJ, Farmer MJ, Melton BE, Sklane S (1981) Effects of feeding level and forage: concentrate ratio on the digestibility of pelleted diets by sheep and cattle. In: Proc of the XIV Int Grass/d Congress, Lexington, Kentucky, USA, 708-710

Hossain W (1960) Evaluation of pipal leaves as feed for goats. Agric Pakist 11, 139-152 
Howe JC, Barry TN, Popay Al (1988) Voluntary intake and digestion of gorse (Ulex Europaeus) by goats and sheep. J Agric Sci Camb 111, 107-114

Huston JE, Rector BS, Ellis WC, Allen MC (1986) Dynamics of digestion in cattle, sheep, goats and deer. J Anim Sci 62, 208-215

Huston JE, Engdahl BS, Bales KW (1988) Intake and digestibility in sheep and goats fed three forages with different levels of supplemental protein. Small Rum Res 1, 81-92

INRA (1988) Alimentation des bovins, ovins et caprins. INRA, Paris, $471 \mathrm{p}$

Jarrige $R$ (1980) Chemical methods for predicting the energy and protein value of forages. Ann Zootech 29 (hors série), 299-323

Jentsch W, Wittenburg $H$, Schiemann $R$ (1988) Studies of the energy requirement of young female cattle. 4. Comparison of the digestibility and of rumen physiologic values of heifers and fully grown sheep. Archiv Anim Nutr $38,2,87-97$

Johnsson S (1972) Digestibility experiments with growing bulls and wethers consuming artificially dried grass. Swedish J Agric Res 2, 97-103

Jones GM, Larsen RE, Javed AH, Donefer $E$, Gaudreau JM (1972) Voluntary intake and nutrient digestibility of forages by goats and sheep. J Anim Sci 34, 5, 830-838

Kay RNB, Goodall ED (1976) The intake, digestibility and retention time of roughage diets by red deer (cervus elaphus) and sheep. Proc Nutr Soc 35, 98A-99A

Kay RNB (1985) Seasonal variation of appetite in ruminants. In: Recent advances in animal nutrition (W Haresign, DJA Cole, eds) Butterworths, London, 199-210

Kayouli C, Jouany JP, Ben Amor J (1991) Comparison of microbial activity in the forestomachs of the dromadery and the sheep measured in vitro and in sacco on mediterranean roughages. Anim Feed Sci Technol 33, $237-$ 245

Kayouli C, Jouany JP, Dardillat C, Tisserand JL (1992) Particularités physiologiques du dromadaire. Conséquences sur son alimentation. Séminaire Dromadaire, octobre, Douz, Tunisie

Kayouli C, Jouany JP, Demeyer DI, Ali-Ali, Taoueb H, Dardillat C (1993) Comparative studies on the degradation and mean retention time of solid and liquid phases in the forestomachs of dromaderies and sheep fed on low-quality roughages from Tunisia. Anim Feed Sci Technol 40, 343-355

Leaver JD, Campling RC, Holmes W (1969) The effect of level of feeding on the digestibility of diets for sheep and cattle. Anim Prod 11, 1118

Maloiy GMO, Kay RNB, Goodall ED (1968) Some effects of nitrogen and water intake in sheep and red deer. Proc Nutr Soc 27, 52A$53 \mathrm{~A}$

Maloiy GMO (1972) Comparative studies on digestion and fermentation rate in the forestomach of the one-humped camel and the zebu steer. Res Vet Sci 13, 476-481

Martin-Rosset W, Andrieu J, Vermorel M, Dulphy JP (1984) Valeur nutritive des aliments pour le cheval. In: Le cheval, reproduction, sélection, alimentation, exploitation ( $R$ Jarrige, W Martin-Rosset, eds). INRA, Paris, 209-238

Martin-Rosset W, Doreau M, Thivend P (1987) Digestion de régimes à base de foin ou d'ensilage de maïs chez le cheval en croissance. Reprod Nutr Dev 27, 291-292

Martin-Rosset W, Dulphy JP (1987) Digestibility interactions between forages and concentrates in horses: influence of feeding level, comparison with sheep. Liv Prod Sci 17, 263276

Martin-Rosset $W$, Doreau M, Boulot S, Miraglia $N$ (1990) influence of level of feeding and physiological state on diet digestibility in light and heavy breed horses. Livest Prod Sci 25, 257-264

Masson C, Alrahmoun W, Tisserand JL (1986) Étude comparée de la quantité ingérée de la digestibilité, de l'utilisation de l'azote, du temps moyen de rétention et du comportement alimentaire chez les jeunes caprins et ovins recevant différents régimes. Ann Zootech 35, 49-60

Masson C, Kirilov D, Faurie F, Tisserand JL (1989) Comparaison des activités alimentaires et méryciques d'ovins et de caprins recevant de la paille d'orge traitée ou non à la soude. Ann Zootech 38, 73-82

McArthur ATG (1957) The ability of cows and calves to digest grass. $N Z J$ Sci Technol 38 , 696-699 
McCabe SM, Barry TN (1988) Nutritive value of willow (Salix sp) for sheep, goats and deer. J Agric Sci Camb 111, 1-9

Mia WH, Sahal B, Majumdar BN, Kehar ND (1960) Studies on tree leaves as cattle fodder. III. The nutrition value of bargad leaves (Ficus Religiosa). Ind J Dairy Sci 13, 1-18

Michalet-Doreau B, Gatel F (1988) Évolution au cours d'une année des quantités de foin ingérées par des béliers castrés. Ann Zootech 37, 151-158

Milne JA, Macrae JC, Spence AM, Wilson S (1978) A comparison of the voluntary intake and digestion of a range of forage at different times of the year by the sheep and the red deer (Cervus elaphus). Br $J$ Nutr 40 , 347-356

Miraglia N, Poncet C, Martin-Rosset W (1994) Effet du niveau d'alimentation, de l'état physiologique et de la race sur le transit dans le tube digestif du cheval. Liv Prod Sci (in press)

Morand-Fehr P, Sauvant D (1978) Chapitre 15 : Caprins. In: Alimentation des ruminants. INRA, Versailles, 449-467

Morand-Fehr P, Hervieu J, Sauvant D (1980) Contribution à la description de la prise alimentaire de la chèvre. Reprod Nutr Dev 20 (5B) 1641-1644

Morand-Fehr P, Sauvant D (1988) Alimentation des caprins. In: Alimentation des bovins, ovins et caprins. INRA, Versailles, 281-304

Playne MJ (1970) Differences in the nutritional value of three cuts of Buffel grass for sheep and cattle. Proc Austr Soc Anim Prod 8, 511516

Playne MJ (1978) Differences between cattle and sheep in their digestion and relative intake of a mature tropical grass hay. Anim Feed Sci Technol 3, 41-49

Poppi DP, Minson DJ, Ternouth JH (1980) Studies of cattle and sheep eating leaf and stem fractions of grasses. I. The voluntary intake, digestibility and retention time in the reticulorumen. Austr J Agric Res 32, 99-108

Prigge EC, Baker MJ, Varga GA (1984) Comparative digestion, rumen fermentation and $\mathrm{ki}-$ netics of forage diets by steers and wethers. J Anim Sci 59, 1, 237-245

Quick TC, Dehority BA (1986) A comparative study of feeding behaviour and digestive function in dairy goats, whool sheep and hair sheep. J Anim Sci 63, 1516-1526

Rees MC, Little DA (1980) Differences between sheep and cattle in digestibility, voluntary intake and retention time in the rumen of three tropical grasses. J Agric Sci Camb 94, 483485

Reid RL, Jung GA, Cox-Ganser JM, Rybeck BE, Townsend EC (1990) Comparative utilization of warm and cool season forages by cattle, sheep and goats. J Anim Sci 68, 2986-2994

Richard D (1989) Ingestibilité et digestibilité des aliments par le dromadaire. In: Options méditerranéennes. Série Séminaires $n^{\circ} 2,55-59$

Ruckebusch Y, Bost J (1963) Étude comparée de la motricité du réticulum et du comportement alimentaire chez les ovins et caprins en stabulation. Rev Med Vet CXIV, 3, 184-195

Samsher J, Majmudar BN (1962) A study on comparative digestibilities in different species of ruminants. Ann Biochem Exp Med 22 (12), 303-308

Schiemann R, Jentsch W, Wittenburg $H$, Hoffmann L (1968) Ergebnisse vergleichender untersuchungen über die verdanlichkeit von rationen bei rind und schof unter besonderer berücksichtigung pansensphysiologischer parameter. Wiss Z Univ Rostock 17, 867876

Sharma VV, Rajora NK (1977) Voluntary intake and nutrient digestibility of low-grade roughage by ruminants. $J$ Agric Sci Camb 88, 75-78

Siebert BD, Kennedy PM (1972) The utilization of spear gras (Heteropogon Contortus). I. Factors limiting intake and utilization by cattle and sheep. Aust J Agric Res 23, 35-44

Slade LM, Hintz HF (1969) Comparison of digestion in horses, ponies, rabbits and guinea pigs. J Anim Sci 28, 842-843

Slade LM, Robinson DW (1970) Nitrogen metabolism in non-ruminant herbivores. II. Comparative aspects of protein digestion. $J$ Anim Sci761-763

Smolders G, Steg A, Hindle VA (1990) Organic matter digestibility in horses and its prediction. Neth J Agric Sci 38, 435-477

Suttie JM, Goodall ED, Pennie K, Kay RNB (1983) Winter food restriction and summer compensation in red deer stags (Cervus Elaphus). Br J Nutr 50, 737-747 
Suttie JM, Corson ID, Fennessy PF (1984) Voluntary intake, testis development and antler growth patterns of male red deer under a manipulated photoperiod. $N Z$ Soc Anim Prod 44, 167-170

Swift RW, Bratzler JW (1959) A comparison of the digestibility of forages by cattle and sheep. Bull 651. The Pennsylvania State University, Agricultural Experiment Station, $5 \mathrm{p}$

Thomas S, Campling RC (1977) Comparisons of some factors affecting digestibility in sheep and cows. J Brit Gras Soc 32, 33-41

Tisserand $\mathrm{JL}$, Hadjipanayiotou M, Gihad EA (1991) Digestion in goats. In: Goat nutrition (P Morand-Fehr, ed) Pudoc, Wageningen, EAAP Publication $n^{\circ} 46,46-60$

Uden P, Van Soest PJ (1982) Comparative digestion of timothy (Phleum pratense) fibre by ruminants, equines and rabbits. Br J Nutr 47 , 267-272

Van der Noot GW, Cordts RH, Hunt R (1965) Comparative nutrient digestibility of silages by cattle and sheep. J Anim Sci 24, 47-50

Van der Noot GW, Gilbreath EB (1970) Comparative digestibility of components of forages by geldings and steers. $J$ Anim Sci 31,351 355

Van Dyne GM, Lofgreen GP (1964) Comparative digestion of dry annual range forage by cattle and sheep. J Anim Sci 23, 823-832

Van Rooyen P, Van der Merwe FJ (1983) Digestibility of the same diet in cattle and sheep. S Afric J Anim Sci 13, 211-212
Van Soest PJ (1980) The limitations of ruminants. Proc Cornell Nutr Conf 78-90

Van Soest PJ (1982) Nutritional ecology of the ruminant. Comstock Publishing Associates, Cornell University Press, Ithaca, 373 p

Vermorel M, Jarrige R, Martin-Rosset W (1984) Métabolisme et besoins énergétiques du cheval. Le système des UFC. In : Le Cheval, reproduction, sélection, alimentation, exploitation (R Jarrige, W Martin-Rosset, eds) INRA, Paris, 239-276

Vona LC, Jung GA, Reid RL, Sharp WC (1984) Nutritive value of warm-season grass hays for beef cattle and sheep digesibility, intake and mineral utilization. $J$ Anim Sci 59, 15821593

Warmington BG, Wilson GF, Barry TN (1989) Voluntary intake and digestion of rye-grass straw by llamaguanaco crossbreds and sheep. J Agric Sci Camb 113, 87-91

Wilkins RJ, Lonsdale CR, Tetlow RM, Forrest TJ (1972) The voluntary intake and digestibility by cattle and sheep of dried grass wafers containing particles of different size. Anim Prod 14, 177-188

Wilson AD (1977) The digestibility and voluntary intake of the leaves of trees and shrubs by sheep and goats. Aust J Agric Res 28, 501508

Wolter R, Chaabouni A (1979) Étude de la digestion de l'amidon chez le cheval par analyse du contenu digestif après abattage. Rev Med Vet 130, 1345-1357 